\title{
Study of fetomaternal outcome in twin pregnancy
}

\author{
Bijal D. Rami, Somika Kaul*
}

Department of Obstetrics and Gynecology, Government Medical College and S.S.G Hospital, Vadodara, Gujarat, India

Received: 17 September 2019

Accepted: 25 October 2019

\section{*Correspondence: \\ Dr. Somika Kaul, \\ E-mail: kaulsomika24@gmail.com}

Copyright: () the author(s), publisher and licensee Medip Academy. This is an open-access article distributed under the terms of the Creative Commons Attribution Non-Commercial License, which permits unrestricted non-commercial use, distribution, and reproduction in any medium, provided the original work is properly cited.

\begin{abstract}
Background: Twin pregnancy being one of the causes of high-risk pregnancy is associated with both maternal and fetal complications. This study aims at analysing the fetal and maternal outcome in such cases. All cases were studied according to their parity, maternal age, fetal presentation, mode of delivery and gestational age.

Methods: This prospective study was conducted at one of the tertiary care teaching institutes over a period of one year from January 2018 to December 2018. Out of a total number of 7295 deliveries, 130 were twin pregnancy. It included all women admitted in labour room with clinical or ultrasound diagnosis of twin pregnancy after 20 weeks of gestation.

Results: In the present study incidence of twin pregnancy was $1.78 \%$. We observed the highest incidence of twins in the age group of 20-29 years. The least incidence was below the age of 20 years. Incidence of twin pregnancy in our study in primipara was $47.7 \%$ and in multipara was $52.3 \%$. Most of the patients (43\%) delivered at 32-36 weeks of gestation. Maternal complications were noticed as anemia in $29.2 \%$ patients, pregnancy induced hypertension in $55.4 \%$ patients, post-partum hemorrhage in $4.6 \%$ patients, polyhydramnios in $3.1 \%$ patients, premature rupture of membranes in $8.5 \%$ patients, gestational diabetes in $0.8 \%$ patients and urinary tract infection in $2.3 \%$ patients. Majority of the patients delivered vaginally (60.8\%), others by lower segment cesarean section (LSCS). In this study $95.8 \%$ babies were low birth weight. There were 34 neonatal deaths (13\%).

Conclusions: Twin pregnancy is a high-risk pregnancy associated with significantly increased maternal morbidity, neonatal morbidity and mortality. Such pregnancies require good antenatal care, early detection of maternal and fetal complications and timely referral to a centre well equipped for management of such cases.
\end{abstract}

Keywords: Low birth weight, Lower segment cesarean section, Maternal outcome, Perinatal outcome, Singleton pregnancy, Twin pregnancy

\section{INTRODUCTION}

Twin pregnancy refers to the presence of two fetuses in the uterus. It results commonly from the fertilization of two separate ova (dizygotic) and about one third of cases arises from division of one fertilized ovum into two separate embryo (monozygotic). ${ }^{1}$ There are considerable ethnic, racial and geographical variations in the frequency of twin pregnancy. The incidence of twinning and higher order pregnancies has increased over last two decades. The greatest contributors are delayed fertility and use of assisted reproductive technologies. ${ }^{2}$ Multiple pregnancies are recognized as high risk pregnancy, associated with increased incidence of adverse pregnancy outcomes and risk for both maternal and fetal morbidity and mortality. ${ }^{3}$ Well known complications of twin pregnancy include abortion, hyperemesis gravidarum, congenital malformations, anemia, pregnancy induced hypertension, intrauterine growth restriction, preterm labour, prelabour rupture of membranes and antepartum hemorrhage. Other complications are fetal malpresentation, polyhydramnios, cord prolapse, cord entanglement, urinary tract infection, 
postpartum haemorrhage, retained second twin and operative vaginal delivery. ${ }^{4-6}$

Prematurity poses the greatest threat to twin, with an associated perinatal mortality rate of 3-8 times that of a singleton pregnancy. ${ }^{1}$ Elective hospitalization for bed rest, prophylactic use of tocolytics and use of cervical encirclage are measures proposed to reduce the high fetal wastage associated with premature labour, but these have not been shown conclusively to be beneficial. ${ }^{4}$

However, during the past decade, maternal nutritional intervention has emerged as the only means that consistently improves outcome in twin pregnancy. ${ }^{7}$ From the available guidelines, it appears that most clinicians would consider non vertex first sets as an indication for cesarean section and vertex first twins as candidate for vaginal delivery. ${ }^{8}$ Controversy exists for vertex, nonvertex pairs. ${ }^{9}$ The purpose of this study was to assess the maternal and fetal outcome in cases of twin pregnancy.

\section{METHODS}

This prospective study was carried out in the department of obstetrics and gynecology, S.S.G. hospital, Baroda for a period of 1 year from January 2018 to December 2018. The total number of confinements were 7295 , out of which 130 were twin pregnancies.

\section{Inclusion criteria}

- Primigravida or multigravida

- Booked or unbooked cases

- Patients admitted in labour room or antenatal ward who delivered with clinical or ultrasound diagnosis of twin pregnancy after 20 weeks of gestation.

All cases were analysed depending on parity, age, fetal presentation, mode of delivery and gestational age at the time of delivery. A detailed history was noted. Detailed systemic examination, abdominal examination and per vaginal examination was done. Progress of labour was monitored. APGAR score of all newborn was noted. Necessary treatment was given to every newborn. Neonatal morbidity was noted. Advice regarding diet, rest, breast feeding, immunization, exercise and contraception was given to all mothers at the time of discharge.

\section{Statistical analysis}

This study was designed to record history, duration of pregnancy, per abdominal examination, per vaginal examination, ultrasound findings, progress of labour, mode of delivery, maternal and fetal outcome. The data was analysed and then presented in simple descriptive statistics using tables after collection. The results were presented as numbers and percentages. The analysed data was compared with different studies and discussed.

\section{RESULTS}

This study included 130 cases of twin pregnancies. We evaluated maternal and neonatal outcome in detail.

Table 1: Maternal age distribution.

\begin{tabular}{|lll|}
\hline Age (in years) & Number of cases & Percentage \\
\hline$<20$ & 9 & $6.9 \%$ \\
\hline $20-29$ & 92 & $70.8 \%$ \\
\hline $30-35$ & 29 & $22.3 \%$ \\
\hline
\end{tabular}

Table 1 shows that the incidence of twin pregnancy was highest $(70.8 \%)$ in the age group of 20-29 years due to this being the age of maximum fertility. Incidence was lowest in age group less than 20 years. Despite the minimal age of Indian marriage being 18 years, there are large number of young girls in lower socio-economic status who are married at an earlier age.

Table 2: Distribution according to parity.

\begin{tabular}{|l|l|l|}
\hline Parity & No. of cases & Percentage \\
\hline Primipara & 62 & $47.7 \%$ \\
\hline Multipara & 68 & $52.3 \%$ \\
\hline
\end{tabular}

Above table shows that the incidence of twin pregnancy in our study in primipara was $47.7 \%$ and in multipara was $52.3 \%$.

Table 3: Gestational age at the time of delivery.

\begin{tabular}{|lll|}
\hline Gestational age in weeks & No. of cases & Percentage \\
\hline$<28$ & 14 & $10.8 \%$ \\
\hline $28-32$ & 22 & $16.9 \%$ \\
\hline $33-36$ & 63 & $48.5 \%$ \\
\hline$>36$ & 31 & $23.8 \%$ \\
\hline
\end{tabular}

Maximum number of cases delivered at gestational age of 33-36 weeks. Preterm labour is one of the most common obstetrical complications among twin pregnancy and a major cause of neonatal morbidity.

Table 4: Maternal complications related to twin pregnancy.

\begin{tabular}{|lll|}
\hline Complication & $\begin{array}{l}\text { No. of } \\
\text { cases }\end{array}$ & Percentage \\
\hline Anemia & 38 & $29.2 \%$ \\
\hline Hypertension in pregnancy & 72 & $55.4 \%$ \\
\hline Polyhydramnios & 4 & $3.1 \%$ \\
\hline Postpartum hemorrhage & 6 & $4.6 \%$ \\
\hline Gestational diabetes & 1 & $0.8 \%$ \\
\hline Urinary tract infection & 3 & $2.3 \%$ \\
\hline
\end{tabular}

Above table shows maternal complications related to twin pregnancy. In this study occurrence of anemia was $29.2 \%$, hypertension $55.4 \%$, polyhydramnios $3.1 \%$, 
postpartum hemorrhage $4.6 \%$, gestational diabetes $0.8 \%$ and urinary tract infection $2.3 \%$. Anemia and hypertension are two most common complications in twin pregnancy. The prevalence of anemia varies place to place. The main reason is higher demand in twin pregnancy resulting in iron, vitamin B12, folic acid deficiency and physiological anemia. Pregnancy induced hypertension is due to exposure to superabundant chorionic villi in twin pregnancy. Post-partum hemorrhage occurs due to more stretching of uterine muscle fibres in such cases. It can be prevented by active management of third stage of labour which we follow routinely in our hospital.

Table 5: Distribution according to the mode of delivery.

\begin{tabular}{|lcc|}
\hline Mode of delivery & No. of cases & Percentage \\
\hline Vaginal delivery & 79 & $60.8 \%$ \\
\hline $\begin{array}{l}\text { Lower segment } \\
\text { cesarean section }\end{array}$ & 51 & $39.2 \%$ \\
\hline
\end{tabular}

Overall incidence of lower segment cesarean section in this study was $39.2 \%$ and of vaginal delivery was $60.8 \%$. The mode of delivery depends on multiple factors like fetal presentation intrapartum fetal monitoring experience of the delivering team, wishes of the mother, pelvic assessment and other risk factors. In the present study the final mode of delivery was decided after a detailed discussion with the mother and the relatives.

Table 6: Distribution as per the birth weight of babies.

\begin{tabular}{|c|c|c|}
\hline Birth weight & $\begin{array}{l}\text { No. of } \\
\text { cases }\end{array}$ & Percentage \\
\hline Less than $1500 \mathrm{gm}$ & 39 & $15 \%$ \\
\hline 1500 to less than $2000 \mathrm{gm}$ & 31 & $11.9 \%$ \\
\hline 2000 to $2500 \mathrm{gm}$ & 179 & $68.8 \%$ \\
\hline More than $2500 \mathrm{gm}$ & 11 & $4.2 \%$ \\
\hline
\end{tabular}

This table shows baby weight at the time of birth. $68.8 \%$ of babies were having birth weight of $2-2.5 \mathrm{~kg}$. Restricted growth and preterm delivery are important causes of increased incidence of low birth weight in twin pregnancy.

\section{DISCUSSION}

An accepted formula for the incidence of multiple pregnancy (Hellins Law) is 1 in 80 births in twin pregnancy, 1 in 802in triplet pregnancy and 1 in 803 in quadruplet pregnancy. In the present study the incidence of twin pregnancy was $1: 56$, which was similar to that seen in study done by Pandole and Swammy et al, in which incidence of twin pregnancy was 1:67. ${ }^{10}$ The incidence of twin pregnancy can also be expressed as percentage. In the present study incidence of twin pregnancy was $1.78 \%$ which correlates with Lata et al, which had the incidence of $1.85 \% .^{11}$ The high incidence of such cases may be because our institute being a tertiary care hospital and maximum number of high-risk patients are referred from other centres.

Incidence of twin pregnancy was highest $(70.8 \%)$ in the age group of 20-29 years. A similar conclusion was drawn in a study by Taj $\mathrm{M}$ et al, in which $62.5 \%$ cases of twin pregnancy were found in the age group of 21-25 years. ${ }^{12}$ The results of present study correlate with a study by Bhavana $\mathrm{S}$ et al, in which the incidence of twin pregnancy was maximum $(73.3 \%)$ in the age group of 20 25 years. $^{13}$

In this study most of the cases (48.5\%) delivered at 3336 weeks of gestation. $16.9 \%$ of cases delivered between 28-32 weeks and $10.8 \%$ delivered at less than 28 weeks. In a study by Mahita Reddy A et al, 56\% cases delivered at more than 34 weeks of gestation. ${ }^{14}$ Preterm labour is a known complication of twin pregnancy. Uterine over distension and mechanical stretching of cervix are few of those factors, held responsible for preterm labour in twin pregnancy. Uterine over-distension in multiple pregnancy can perhaps contribute to higher rates of short cervix and therefore higher rates of prematurity. ${ }^{15}$

Incidence of twin pregnancy in our study in primipara was $47.7 \%$ and in multipara was $52.3 \%$. According to the study by Lata et al, the incidence of twin pregnancy was $70.7 \%$ in multigravida and $29.3 \%$ in primigravida. ${ }^{11}$

Majority of the cases delivered vaginally (60.8\%) and $39.2 \%$ of cases delivered by lower segment cesarean section, which correlate with Bangal et al, were cesarean section rate was $33 \% .^{16}$

Maternal complications were noticed as anemia in $29.2 \%$ patients. This correlates with the results from study done by Brown et al, in which incidence of anemia was $35.5 \% .{ }^{17}$ However as per Bhalla $\mathrm{S}$ et al, incidence of anemia in twin pregnancy was $62 \% .{ }^{18}$ The difference in incidence of anemia could be due to variation of prevalence of anemia in different regions. Twin pregnancy is more prone to develop anemia as there is increased fetal demand. In the present study incidence of pregnancy induced hypertension was $55.4 \%$. Large placental surface exposes the mother to more paternal antigen and secreted hormones contribute to hypertension. Post-partum hemorrhage was observed in $4.6 \%$ of cases, polyhydramnios in $3.1 \%$ cases, premature rupture of membranes in $8.5 \%$ cases, gestational diabetes in $0.8 \%$ cases and urinary tract infection in $2.3 \%$ cases. In a similar study done by Taj $\mathrm{M}$ et al, the occurrence of anemia was $27.1 \%$, hypertension $70.8 \%$, polyhydramnios $8.3 \%$, postpartum hemorrhage $27.1 \%$ and gestational diabetes $4.2 \% .^{12}$

In this study 249 babies were born with a birth weight of $2.5 \mathrm{~kg}$ or less. In the study done by Taj $\mathrm{M}$ et al, $79.2 \%$ babies were low birth weight. ${ }^{12}$ Furthermore, in the present study there were 34 neonatal deaths (13\%) which 
correlates with the study done by Bhalla $\mathrm{S}$ et al, in which neonatal deaths at 1 week was $12 \% .^{18}$

\section{CONCLUSION}

To conclude twin pregnancy is associated with increased maternal and perinatal risks. There is a need for specialized antenatal care to reduce complications and adverse outcome. It also requires early diagnosis, regular antenatal care, good intranatal care and intensive neonatal care.

Funding: No funding sources Conflict of interest: None declared

Ethical approval: Not required

\section{REFERENCES}

1. Nkyekyer K. Multiple pregnancy. In: Kwawukwume EY, Emuveyan EE, editors. Comprehensive obstetrics in the Tropics. Accra, Ghana: Asante and Hittscher Printing Press Ltd; 2002.

2. Walker MC, Murphy KE, Pan S, Yang Q, Wen SW. Adverse maternal outcomes in multifetal pregnancies. Br J Obstet Gynecol. 2004;111:1294-6.

3. Conde-Agudelo A, Belizan JM, Lindmark G. Maternal morbidity and mortality associated with multiple gestation. Obstet Gynecol. 2000;95:899904.

4. Martin JA, Hamilton BE, Sutton PD, Ventura SJ, Menacker F, Munson ML. Births: final data for 2002. Natl Vital Stat Report. 2003;52:1-113.

5. Pernoll ML, Melissa M. Multiple pregnancy. In: Decherney DH, Pernoll ML, editors. Current obstetric and gynaecologic diagnosis and treatment, 9th ed. New York, NY: Mc Graw Hill and Large medical books; 2003.

6. Luke B. Improving multiple pregnancy outcomes with nutritional intervention. Clin Obstet Gynecol. 2004;47:146-62.

7. Blickstein I, Goldman RD, Kupfermic M. Delivery of breech first twin: a multicentre retrospective study. Obstet Gynecol. 2000;95:37-42.

8. Hogle KI, Hutton EK, Mcbrien KA, Barret JF, Hannah ME. Cesarean delivery for twin: a systematic review and meta -analysis. Am. J Obstet Gynecol. 2003;88:220-7.

9. Sunday-Adeoye I, Twomey ED, Egwuatu VE. Births at mater Misericordiae hospital, Afikpo, South Eastern Nigeria. Niger J Clin Pract. 2008;11:231-4.

10. Pandole A, Swamy MS, Sardeshpande N, Mishra A, Kore SJ, Ambiye VR. Perinatal mortality in twin pregnancy: a retrospective analysis. J. Obstet. Gynecol. Ind. 2003;53(2):138-9.

11. Singh L, Trivedi K. Study of maternal and fetal outcome in twin pregnancy. Int J Reprod Contracept Obstet Gynecol. 2017;6:2272-8.

12. Mobeen SV, Jayasri S. Incidence of vaginal delivery versus caesarean section in twin pregnancy in primigravida and its maternal and fetal outcome. IOSR J Dent Med Sci. 2019;18(4):65-71.

13. Bhavana S, Shivanna S, Gopal N. A study on fetomaternal outcome in twin gestation in a tertiary rural health centre. Int $\mathbf{J}$ Adv Res Med Sci. 2014;1(1):15-7.

14. Reddy A, Madhavi KSS, Niharica. A study on risk of twin pregnancy. Int Arch Int Med. 2016;3(10):13945.

15. Franca MS, Tatiana E. N. K. Hamamoto, Antonio AF. (December $14^{\text {th }} 2018$ ). Preterm Birth in Twins, Multiple Pregnancy - New Challenges, Julio Elito Jr. Intech Open , intechopen ; 2014:82447.

16. Bangal VB, Patel SM, Khairnar DN. Study of maternal and foetal outcome in twin gestation at tertiary care teaching hospital. IJBAR. 2012;3(10):758.

17. Brown EJ, Dixon HG. Twin pregnancy. J Obstet Gynecol Br Common. 1963;70:251.

18. Bhalla S, Bhatti SG, Devgan S. Obstetric and perinatal outcome of twin pregnancy: a prospective study in a tertiary care hospital in north India. Int $\mathbf{J}$ Repro Contracept Obstet Gynecol. 2018;7(6):245561.

Cite this article as: Rami BD, Kaul S. Study of fetomaternal outcome in twin pregnancy. Int J Reprod Contracept Obstet Gynecol 2019;8:4762-5. 